\title{
Post Traumatic Bilateral TMJ Ankylosis As A Delayed Complication Treated By Interpositional Arthroplasty
}

Srutha Keerthi Gangu ${ }^{1}$, Pavan Kumar Batchu², Haripriya Chari ${ }^{3}$, Yashwanth Yadav ${ }^{4}$

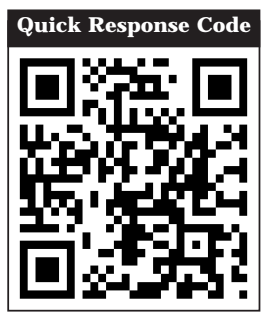

doi: $10.5866 / 2017.9 .10124$

${ }^{1}$ Post Graduate Student

2Prof \& HOD

${ }^{3 \& 4}$ Senior Lecturer

Department of Oral and Maxillofacial Surgery

Kamineni Institute of Dental Sciences

Narketpally, Nalgonda

\section{Article Info:}

Received: April 10, 2017

Review Completed: May 9, 2017

Accepted: J une 12, 2017

Available Online: J une, 2017 (www.nacd.in)

(c) NAD, 2017 - All rights reserved

\section{Email for correspondence:}

srutha.g@gmail.com

\begin{abstract}
:
The present article describes a case of post traumatic complete bilateral bony ankylosis with $10 \mathrm{~mm}$ of maximum mouth opening. Patient had history of bilateral condylar fracture and had been treated before 4 years by ORIF, gradually his mouth opening started diminishing and radiographic examination revealed bilateral bony ankylosis as well as presence of a 4 holed plate and screws on lateral aspect of the left condylar region. Ankylotic mass removed bilaterally and temporalis myofacial flap is used to interpose between the osteotomised segements to prevent chances for reankylosis. Post operative aggressive physiotherapy for 1 year post operatively maintained a maximum of $35 \mathrm{~mm}$ mouth opening.
\end{abstract}

Key words: ankyl osis, temporal is myofacial flap, interpositional arthroplasty, TMJ .

\section{INTRODUCTION}

Temporomandibular joint (TMJ ) Ankylosis is a condition that causes problems in opening of mouth, mastication, speech, and maintenance of oral hygiene. Ankylosis of the TMJ classified depending on the site (intra-articular or extra-articular), type of tissue (bony, fibrous, fibro-osseous), and extent of fusion (complete or incomplete). Tripathy et al have classified ankylosis as true or false. In true ankylosis there is bony or fibrous adhesion between the surfaces of the joint within the capsule, whereas in false ankylosis the problems liein the surrounding structures. Various procedures for the treatment include gap arthroplasty (GA), interpositional gap arthroplasty (IPG), and/or total joint reconstruction using autogenous grafts or alloplastic materials. ${ }^{1,2}$

\section{CASE REPORT}

A 26 years male patient reported to the department of oral and maxillofacial surgery with a chief complaint of inability to open the mouth since 
a year. Patient had history of bilaterally fractured condyles after a road traffic accident and had been treated by ORIF four years ago. Patient had lost his upper anterior teeth during accident. Patients gives history of normal mouth opening initially, which then started to gradually decrease, but there was no associated pain.Patient was able to manage to eat from the gap created from edentulous anterior region. Patient underwent prosthetic rehabilitation of anterior region with fixed partial denture oneyear previously, because of which the anterior gap was reduced. Patient encountered huge difficulty in eating and speaking. Patient's mouth opening at the time of examination was $10 \mathrm{~mm}$..

On clinical examination, apart from restricted mouth opening there was an inability to frown on left side due to facial nerve palsy suggesting damaged temporal branch of facial nerve on left side and the remaining branches are intact as examined. There was no facial asymmetry, there was loss of antegonial notch bilaterally, no other extra oral abnormalities detected. Intra orally, there is class I occlusion and maximum mouth opening is $10 \mathrm{~mm}$, missing upper anterior teeth replaced by fixed partial denture, no other hard tissue or soft tissue abnormalities are detected. Radiographic examination using OPG shows haphazardly placed condylar heads and glenoid fossa and unidentifiable joint space bilaterally and presence of 4 holed mono cortical plate with screws on lateral boder of the left condyle (Figure 1). CT scan shows that there was a bilateral complete three dimensional bony ankylosis with no internal anatomy left (Figure 2).

Interpositional arthroplasty was planned under general anesthesia. After intubation the patient was painted with $7.5 \%$ Betadine and draped. The external auditory canal was packed with Vaseline ribbon gauze.The incision was outlined at the junction of facial skin with the helix of the ear. The incision was extended superiorly from the top of the helix as described by Bramley. AlKayat-Brahmley incision (Figure 3) was given, blunt dissection was done to identify trunk and branches of facial nerve, the fascia, along with the facial nerve, was retracted and the exposure of the articular eminence of the TMJ was done. Osteotomy cut was made using bur just below the squamous part of temporal bone and an another cut is made just $1.5 \mathrm{~cm}$ below to the initial cut about $1.5 \mathrm{~cm}$ bony wedge was removed by chisel, the residual mono cortical plates and screws were removed. Lower stump was re-contoured to simulate condyle to avoid any sharp margins. Mouth opening intra operatively achieved about 42mm (Figure 4). Dissection of superficial temporalis muscle (Figure 5) was done and it was atraumatically auto rotated towards the joint space and placed between the osteotomised segments in a fashion fascia directing towards glenoid fossa and muscle directing towards the shaped condyle. Incision closed in layers using polyglycolic acid and skin suturing done using non absorbable polypropylene sutures. Drains were placed bilaterally and removed on $5^{\text {th }}$ post operative day. There is no post operative facial muscle weakness. Skin sutures were removed and active physiotherapy initiated under supervision with 5days a week for initial 1 month then at home unsupervised for 3 months, patient was followed for 1 year for every 3 months and the maintained satisfactory mouth opening is about $35 \mathrm{~mm}$ (Figure $6)$.

\section{DISCUSSION}

Ankylosis of the TMJ is most challenging for both patient and surgeon. There are many surgical procedures for correcting the problem exists but still there is no consensus presents. A variety of techniques for treatment of TMJ ankylosis have been described in the literature. Before Esmarch's body ostectomy in 1851, ankylosis wasthought to be incurable. Humphrey performed the first condylectomy for ankylosis in 1854. Gap arthroplasty at least $1 \mathrm{~cm}$ to prevent reankylosis ${ }^{6}$ was advocated by Abbe in 1880, and refined byRisdon in 1934. Until Risdon used interpositional materials, the treatment of ankylosis was fraught withrecurrence. Numerous autogenous materials have been used as interpositional materials, including temporalis myofascial flap (Golovine, 1898), fascia lata, auricular cartilage, dermis, fullthickness skin, fourth metatarsal (Bardenheur, 1909), costochondral graft (Gillies, 1920), second metatarsal (Entin et al, 1968), sterno clavicular joint, ulnar head, rib, calvarial bone, fibula, and iliac bone. ${ }^{3,4}$ Various alloplastic materials have al so been used including wooden block (Murray Carnochan, 


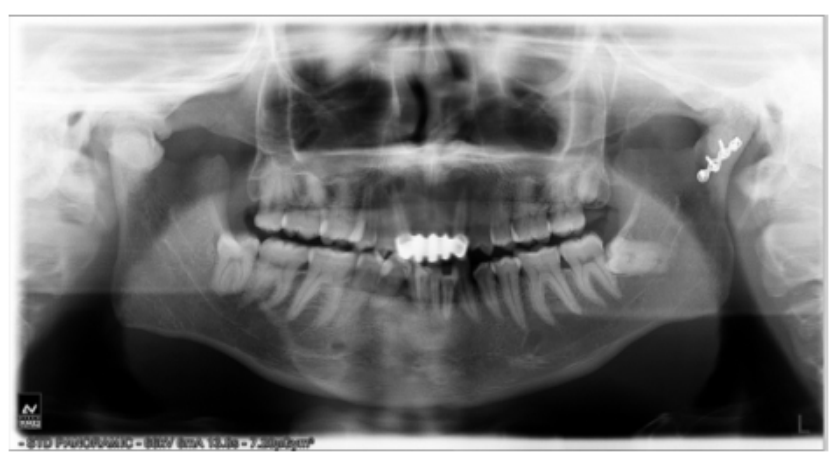

Figure 1: Preoperative radiograph showing displaced condyle on the right side and obliteration of joint spaces bilaterally.

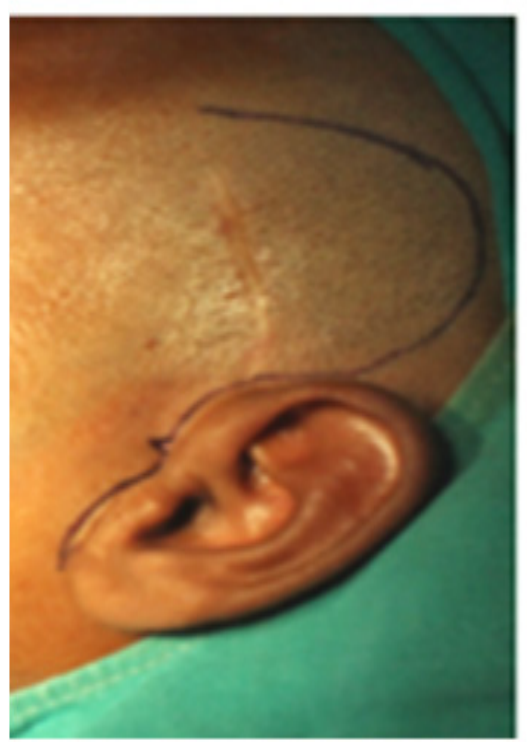

Figure 3: Intraoperative photograph showing markings for Al-KayatBrahmley incision.

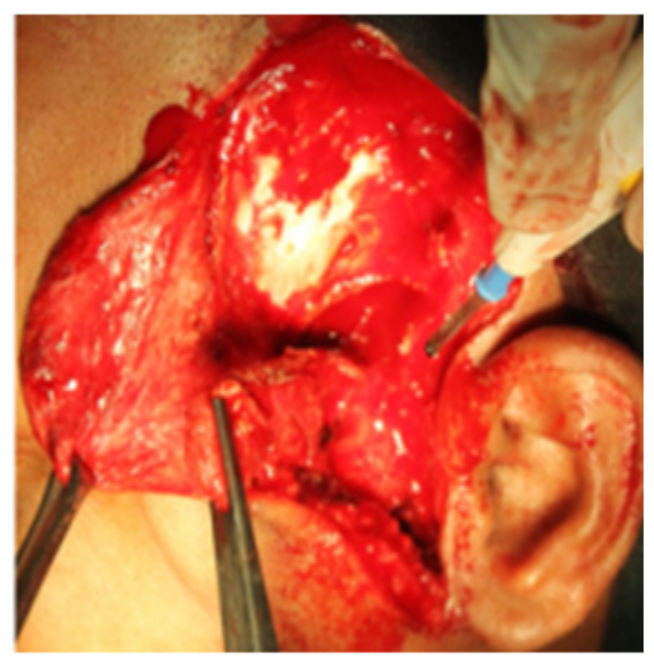

Figure 5: Intraoperative photograph showing dissection of temporalis muscle for interposition.

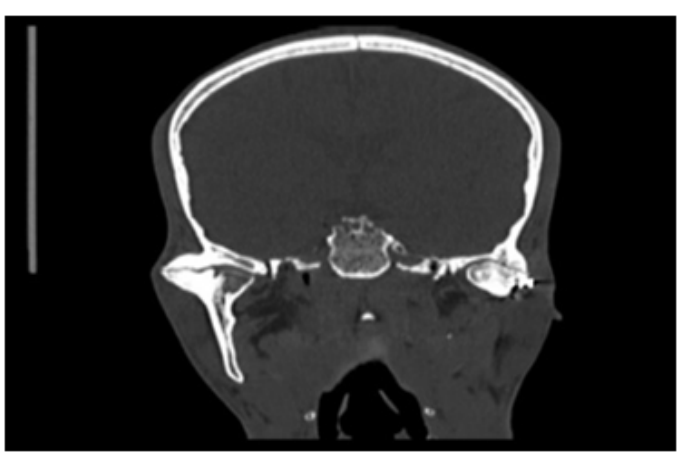

Figure 2: Preoperative CT- Coronal section showing ankylotic mass extending till medial aspect and obliteration of joint spaces bilaterally

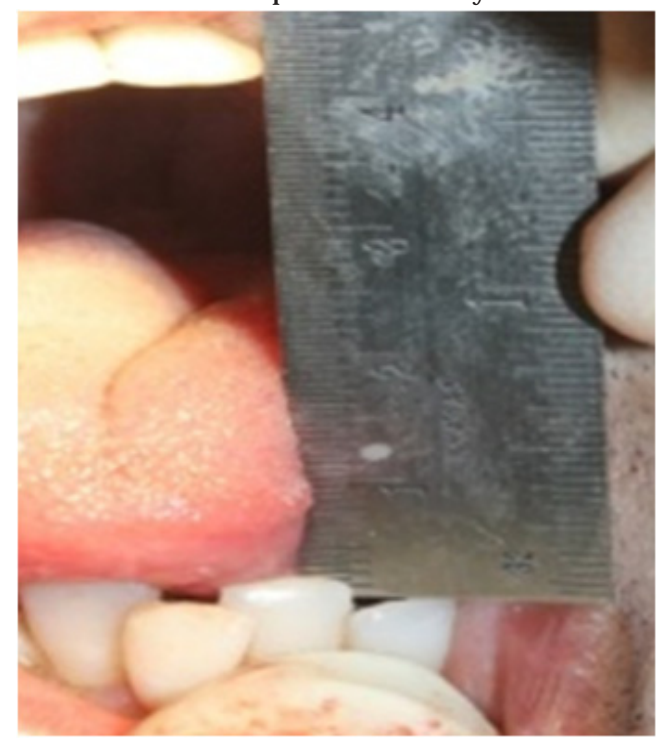

Figure 4: Intraoperative photograph showing intraoperative mouth opening

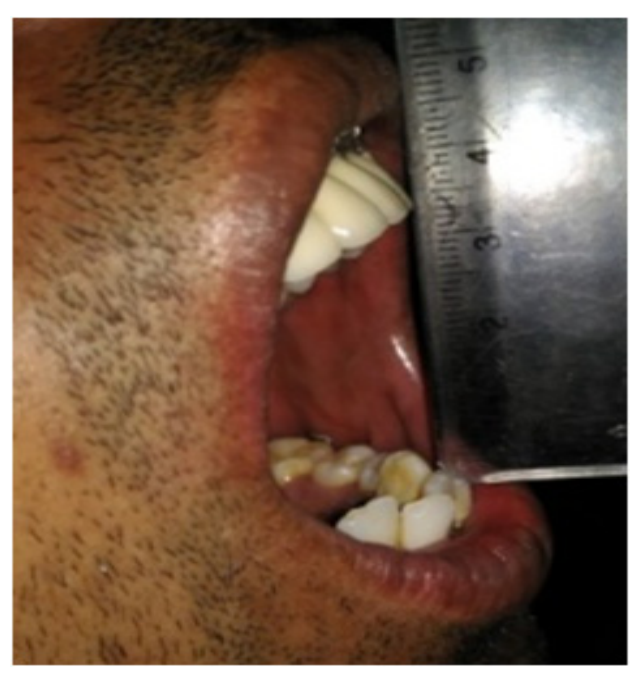

Figure 6: Post operative photograph showing mouth opening 1 year after surgery. 
1880), gold foil (Risdon, 1933), tantalum foil (Egners, 1946), Silastic (Robinson, 1968), proplast, Teflon, ticonium, stainless steel, acrylic, vitallium, silicone rubber prosthesis, and total metal joint prostheses. ${ }^{2}$ Kaban (1990) had given a protocol that included:aggressive resection of the ankylotic segment, ipsilateral coronoidectomy, contralateral coronoi dectomy when necessary, lining the joint with temporalis fascia or cartilage, reconstruction of the ramus with costocondral graft, rigid fixation of the graft, early mobilization and aggressive physiotherapy. ${ }^{1,5-7}$ Temporal is myofacial flap reduces chances for reankylosis and also maintains the vertical height of the ramus of the mandible gives promising results. Despite of various surgical procedures, meticulous removal of ankylotic mass and postoperative aggressive physiotherapy for longer period of time determines the final results.

\section{REFERENCES}

1. J ulieAnn Smith et al. Subjective and Objective Assessment of the Temporalis Myofascial Flap in Previously Operated Temporomandibular J oints. J Oral Maxillofac Surg 1999; 57(10):58-65.
2. Tyman P. Loveless et al.Efficacy of Temporomandibular J oint Ankylosis Surgical Treatment. J Oral Maxill ofac Surg 2010; 68:1276-82.

3. Hironobu Umedaetal. Long-Term Viability of the Temporalis Muscle/Fascia Flap Used for Temporomandibular J oint Reconstruction. J Oral Maxillofac Surg 199; 51:530-3.

4. Alonso Del Hoyoetal J. The Temporalis Muscle Flap: An Evaluation and Review of 38 Cases. J oral Maxillofac Surg 1994; 52:143-7.

5. Anil K. Danda et al. Comparison of Gap Arthroplasty With and Without a Temporalis Muscle Flap for the Treatment of Ankylosis. J Oral Maxillofac Surg 2009; 67:1425-31.

6. Su Gwan K et al. Treatment of temporomandibular joint ankylosis with temporalis muscleand fascia flap. Int. J Oral Maxillofac Surg 2001; 30:189-93.

7. Omura S et al. Modification of the Temporal is Muscle and Fascia Flap for the Management of Ankylosis of the Temporomandibular J oint. J Oral Maxdlofac Surg 1996; 54:794-5.

\section{Gain quick access to our journal online View our journal at www.nacd.in}

